\title{
Influência de Diferentes Níveis de Ácido Fumárico sobre o Desempenho de Coelhos em Crescimento
}

\author{
Claudio Scapinello ${ }^{1}$ Antonio Claudio Furlan ${ }^{1}$, Haroldo Garcia de Faria ${ }^{2}$
}

\begin{abstract}
RESUMO - Este experimento foi realizado para avaliar o efeito da adição de diferentes níveis de ácido fumárico às rações $(0,0 ; 0,5$; 1,0; 1,5; e 2,0\%) sobre o desempenho de coelhos em crescimento. Cinquenta coelhos da raça Nova Zelândia Branco, 25 machos e 25 fêmeas, de 40 a 80 dias de idade foram distribuídos em delineamento experimental em blocos casualizados, com cinco tratamentos e 10 repetições com um animal por unidade experimental. A adição do ácido fumárico às rações não influiu no desempenho dos coelhos em nenhum dos níveis estudados, até 70 dias de idade. Considerando o período total do experimento, de 40 a 80 dias de idade, a inclusão de $2,0 \%$ de ácido fumárico melhorou a conversão alimentar. As demais características de desempenho e rendimento de carcaça não foram influenciadas pela adição de ácido fumárico. Adição de 2,0\% de ácido fumárico à ração de coelhos melhorou a conversão alimentar de coelhos no período de 40 a 80 dias de idade.
\end{abstract}

Palavras-chave: ácido fumárico, coelhos, desempenho

\section{Effect of Different Levels of Fumaric Acid on the Performance of Growing Rabbits}

ABSTRACT - This experiment was conducted to evaluate the effect of the addition of different levels of fumaric acid to diet $(.0, .5,1.0,1.5$, and $2,0 \%)$ on the performance of growing rabbits. Fifty rabbits of White New Zealand breed, 25 males and 25 females, from 40 to 80 days of age were alloted to a randomized blocks experimental design with five treatments and ten replicates with one animal per experimental unit. The addition of fumaric acid to the diets did not affect the rabbits performance in anyone of the studied levels up to 70 days of age. Considering the total experimental period from 40 to 80 days of age, the addition of $2.0 \%$ fumaric acid improved the feed:gain ratio. The other performance characteristics and carcass yield were not affected by the addition of fumaric acid. The addition of $2.0 \%$ of fumaric acid to the rabbit diets improved the feed:gain ratio of the rabbits in the period from 40 to 80 days age.

Key Words: fumaric acid, rabbits, performance

\section{Introdução}

A administração de agentes acidificantes às rações, como ácidos orgânicos, apresentam efeitos benéficos, especialmente na saúde do trato digestivo dos animais. Probióticos, cultura de leveduras e ácidos orgânicos têm demonstrado ótimos resultados em numerosas espécies animais, principalmente em animais jovens e adultos em estado de estresse (HOLLISTER et al., 1989).

Os ácidos orgânicos são utilizados em rações de animais recém-desmamados, em função destes apresentarem um sistema digestivo relativamente imaturo e não digerirem os carboidratos e proteínas contidas nos grãos de cereais e de sementes oleaginosas tão eficientemente quanto os carboidratos do leite (lactose) e as proteínas do leite (caseína, lactoalbumina). Isto se deve, em parte, à insuficiente quantidade de secreção de enzimas digestivas e à inadequada produção de ácido clorídrico pelo estômago (CROMWELL, 1989).

Diminuição do $\mathrm{pH}$ no intestino e incremento na atividade da pepsina no estômago podem ser atribuídos aos ácidos orgânicos. Com a redução do pH intestinal, não há proliferação de E. coli e outros microorganismos patógenos no estômago e intestino delgado, os quais competem com o animal, pelos nutrientes, além de causarem inúmeros distúrbios no trato gastro intestinal.

Segundo PATTEN e WALDROUP (1988), a adição de ácidos orgânicos na dieta animal melhora a eficiência alimentar e a velocidade de crescimento.

Alguns estudos com coelhos foram realizados no sentido de se demonstrar a eficácia de ácidos orgânicos, seja na melhora de desempenho ou no controle de microorganismos patógenos no trato digestivo (GRAZIOLI et al., 1986; CASTROVILLI, 1991; e GEDEK et al., 1992). 
O objetivo do presente experimento foi estudar a influência de diferentes níveis de ácido fumárico sobre o desempenho de coelhos em crescimento.

\section{Material e Métodos}

O experimento foi conduzido no setor de Cunicultura da Fazenda Experimental de Iguatemi, no período de abril a junho de 1996. Foram utilizados 50 coelhos da Raça Nova Zelândia Branco, 25 machos e 25 fêmeas, com 40 dias de idade, alojados em gaiolas de arame galvanizado, providas de bebedouro automático e comedouro semi-automático de chapa galvanizada, localizados em galpão de alvenaria, com cobertura de telha francesa, pé direito de 3,0 metros, piso de alvenaria, paredes laterais de $50 \mathrm{~cm}$ em alvenaria e o restante em tela e cortina de plástico para controle de ventos. A temperatura média registrada no período experimental foi de $21^{\circ} \mathrm{C}$, sendo que a máxima registrada foi de $22^{\circ} \mathrm{C}$ e a mínima, $19^{\circ} \mathrm{C}$.

Os animais foram distribuídos em delineamento experimental em blocos casualizados com cinco tratamentos e dez repetições por tratamento, com um animal por unidade experimental.

A ração utilizada no experimento foi formulada com base nas exigências do AEC (1987) para coelhos em crescimento, sendo considerada a análise dos ingredientes. Foi formulada uma ração testemunha e quatro rações contendo níveis de ácido fumárico $(0,5 ; 1,0 ; 1,5 ;$ e $2,0 \%)$.

$\mathrm{O}$ fornecimento das rações e da água foi à vontade. A composição centesimal e química das rações experimentais encontra-se na Tabela 1.

Os coelhos foram pesados no início do experimento com 40 dias de idade, aos 70 dias de idade, e no final do experimento com 80 dias.

O modelo estatístico utilizado foi:

$\mathrm{Y}_{\mathrm{ijk}}=\mu+\mathrm{b}_{1}\left(\mathrm{~A}_{\mathrm{i}}-\mathrm{A}\right)+\mathrm{b}_{2}\left(\mathrm{~A}_{\mathrm{i}}-\mathrm{A}\right)^{2}+\mathrm{B}_{\mathrm{j}}+\mathrm{e}_{\mathrm{ijk}}$ em que

$\mathrm{Y}_{\mathrm{ijk}}=$ valor observado da variável estudada, relativo a cada indivíduo $\mathrm{k}$ do bloco j, recebendo o nível i de ácido fumárico na ração;

$\mu=$ constante geral;

$\mathrm{b}_{1}=$ coeficiente de regressão linear da variável y, em função dos níveis i de ácido fumárico às rações, para todo i diferente de 1 ;

$\mathrm{b}_{2}=$ coeficiente de regressão quadrático da variável y, em função dos níveis i de ácido fumárico às rações, para todo i diferente de 1 ;

$\mathrm{A}_{\mathrm{i}}=$ nível de adição de ácido fumárico i, sendo $\mathrm{i}=0 ; 0,5 ; 1,0 ; 1,5 ;$ e $2,0 \%$;

A = nível médio de adição de ácido fumárico às rações;

$\mathrm{B}_{\mathrm{j}}=$ efeito do bloco $\mathrm{j}$; e

$\mathrm{e}_{\mathrm{ijk}}=$ erro aleatório associado a cada observação.

Com a ração testemunha incluída na análise de variância, utilizou-se o teste Dunnett $(\mathrm{P}<0,05)$ para comparação das suas médias com as médias das características estudadas, obtidas com as rações com os diferentes níveis de ácido fumárico.

\section{Resultados e Discussão}

O peso vivo dos coelhos aos 70 dias de idade, o consumo de ração diário, o ganho de peso diário e a conversão alimentar de 40 a 70 dias de idade, de acordo com os diferentes níveis de adição de ácido fumárico nas rações, encontram-se na Tabela 2.

Utilizando-se o teste Dunnett, verificou-se que as características estudadas, nos animais que receberam rações contendo níveis de ácido fumárico, não apresentaram diferença em relação às dos animais que receberam a ração testemunha.

A análise de regressão demonstrou não haver efeito da adição de ácido fumárico sobre o peso vivo aos 70 dias de idade, consumo de ração, ganho de peso diário e a conversão alimentar no período de 40 a 70 dias de idade.

Estes resultados diferem dos obtidos por CASTROVILLI (1991), que, trabalhando com coelhos mestiços de peso entre 900 e 1100 g, com misturas de ácidos orgânicos e inorgânicos (ácido fosfórico, ácido acético, ácidoláctico, ácido tártarico e ácido málico), concluiu que a adição de $0,3 \%$ destes ácidos à ração provocou melhoras no ganho de peso, na conversão alimentar e nos processos digestivos.

FALKOWSKI e AHERNE (1984), também trabalhando com suínos desmamados, observaram que a adição de 1 ou $2 \%$ de ácido fumárico ou cítrico, durante a semana pós desmama, provocou melhoras na conversão alimentar e no ganho médio de peso diário.

A falta de resposta à acidificação das rações pode estar associada a alguns fatores, como o tempo pós-desmama e o tipo e a dosagem do acidificante. $\mathrm{O}$ tempo pós-desmama é fator importante, pois a resposta à acidificação ocorre por um período pequeno pós-desmama. GIESTING et al. (1991) afirmam que a resposta à acidificação é mais evidente logo após o declínio do desmame com a idade. 
Rev. bras. zootec.

Tabela 1 - Composição percentual das rações experimentais

Table 1 - Percentage composition of the experimental diets

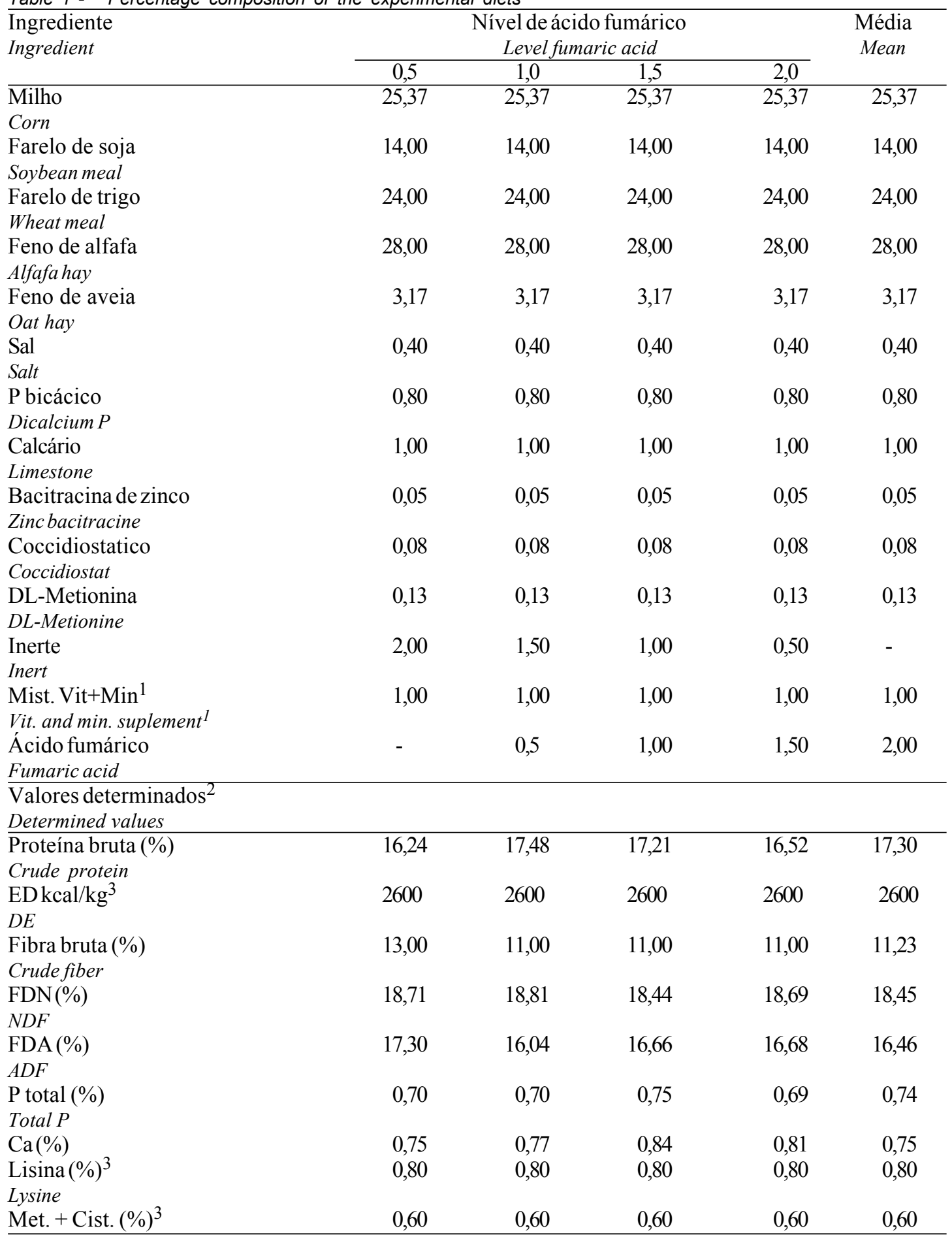

${ }^{1}$ Composição por quilo (Composition per kg): Vit A., 300.00 UI; Vit $D_{3}, 50.000$ UI; Vit E, 4.000 mg; Vit K ${ }_{3}, 100 \mathrm{mg}$; Vit $B_{1}$, 200 mg; Vit $B_{2}, 300$ mg; Vit $B_{6}, 100$ mg; Vit $B_{12}, 1.000$ mg; Ácido nicotínico (Nicotinic ac.), 1.500 mg; Ácido pantotenico (Panthotenic ac.), $1.000 \mathrm{mg}$; Colina (Choline), $35.000 \mathrm{mg} ; \mathrm{Fe}, 4.000 \mathrm{mg} ; \mathrm{Cu}, 600 \mathrm{mg}$; Co, $100 \mathrm{mg}$; Mn, 4.300 mg; Zn, 6.000 mg; I, 32 mg; Se, 8 mg; Met, (Meth) 60.000 mg; Promotor de crescimento (Growth promoter), $1.500 \mathrm{mg}$; Coccidiostatico (Coccidiostat), $12.500 \mathrm{mg}$; Antioxidante (Antioxidant) $10.000 \mathrm{mg}$.

${ }^{2}$ Análise realizada no Laboratório de Nutrição Animal do Departamento de Zootecnia da Universidade Estadual de Maringá.

${ }^{3}$ De acordo com a composição dos alimentos e das tabelas.

${ }^{2}$ Analysis carried out in Animal Nutrition Lab of Animal Science Departament of State University of Maringá.

${ }^{3}$ According to the tables and feed composition. 
SCAPINELLO et al.

Tabela 2 - Média de PV aos 70 dias, ganho de peso diário, consumo de ração diário e conversão alimentar de coelhos de 40 a 70 dias de idade, de acordo com diferentes níveis de adição de ácido fumárico nas rações

Table 2 - Mean of LW, daily weigt gain, daily diet intake and feed:gain ratio of rabbits from 40 to70 days age according to different levels of fumaric acid addition to the diets

\begin{tabular}{|c|c|c|c|c|c|c|}
\hline \multirow[t]{2}{*}{$\begin{array}{l}\text { Sexo } \\
\text { Sex }\end{array}$} & \multirow[t]{2}{*}{$\begin{array}{l}\text { Test. } \\
\text { Control }\end{array}$} & \multicolumn{4}{|c|}{$\begin{array}{l}\text { Nível de ácido fumárico } \\
\text { Level fumaric acid }\end{array}$} & \multirow[t]{2}{*}{$\begin{array}{l}\text { Média } \\
\text { Mean }\end{array}$} \\
\hline & & 0,5 & 1,0 & 1,5 & 2,0 & \\
\hline \multicolumn{7}{|c|}{$\begin{array}{l}\mathrm{PV} \text { aos } 70 \text { dias }(\mathrm{g}) \\
L W \text { at } 70 \text { days }\end{array}$} \\
\hline $\begin{array}{l}\text { Macho } \\
\text { Male }\end{array}$ & 2115 & 2234 & 2167 & 2132 & 2374 & 2204 \\
\hline $\begin{array}{l}\text { Fêmea } \\
\text { Female }\end{array}$ & 2181 & 2172 & 2086 & 1979 & 2124 & 2108 \\
\hline $\begin{array}{l}\text { Média } \\
\text { Mean }\end{array}$ & 2148 & 2203 & 2118 & 2056 & 2249 & 2156 \\
\hline \multicolumn{7}{|c|}{$\begin{array}{c}\text { Ganho de peso diário }(\mathrm{g}) \\
\text { Daily weight gain }\end{array}$} \\
\hline $\begin{array}{l}\text { Macho } \\
\text { Male }\end{array}$ & 36 & 40 & 38 & 37 & 45 & 39 \\
\hline $\begin{array}{l}\text { Fêmea } \\
\text { Female }\end{array}$ & 39 & 38 & 35 & 32 & 37 & 36 \\
\hline $\begin{array}{l}\text { Média } \\
\text { Mean }\end{array}$ & 38 & 39 & 37 & 35 & 41 & 38 \\
\hline \multicolumn{7}{|c|}{$\begin{array}{c}\text { Consumo de ração diário }(\mathrm{g}) \\
\text { Daily feed intake }\end{array}$} \\
\hline $\begin{array}{l}\text { Macho } \\
\text { Male }\end{array}$ & 126 & 127 & 134 & 120 & 129 & 127 \\
\hline $\begin{array}{l}\text { Fêmea } \\
\text { Female }\end{array}$ & 125 & 126 & 124 & 128 & 128 & 126 \\
\hline $\begin{array}{l}\text { Média } \\
\text { Mean }\end{array}$ & 126 & 126 & 129 & 124 & 129 & 127 \\
\hline \multicolumn{7}{|c|}{$\begin{array}{l}\text { Conversão alimentar } \\
\text { Feed:gain ratio }\end{array}$} \\
\hline $\begin{array}{l}\text { Macho } \\
\text { Male }\end{array}$ & 3,62 & 3,17 & 3,61 & 3,37 & 2,93 & 3,34 \\
\hline $\begin{array}{l}\text { Fêmea } \\
\text { Female }\end{array}$ & 3,22 & 3,27 & 3,52 & 5,37 & 4,26 & 3,92 \\
\hline $\begin{array}{l}\text { Média } \\
\text { Mean }\end{array}$ & 3,42 & 3,22 & 3,56 & 4,37 & 3,59 & 3,63 \\
\hline
\end{tabular}

A capacidade acidificante é identificada pela constante de dissociação do ácido; assim, a constante de dissociação esta relacionada com o tipo e a dosagem do ácido. GARDENER (1972) afirma que a constante de dissociação e a solubilidade em água dos diferentes ácidos podem ser fatores que influem nas resposta à acidificação.

O peso vivo dos coelhos aos 80 dias, o ganho de diário, o consumo de ração diário e a conversão alimentar de coelhos de 40 a 80 dias de idade, de acordo com diferentes níveis de inclusão de ácido fumárico às rações, encontram-se na Tabela 3.

O teste Dunnett demonstrou que apenas a conversão alimentar dos animais que receberam ração contendo $2 \%$ de ácido fumárico foi melhor $(\mathrm{P}<0,05)$ em relação à dos animais que receberam a ração testemunha.

A análise de regressão demonstrou efeito quadrático $(\mathrm{P}<0,05)$ sobre a conversão alimentar no período de 40 a 80 dias de idade.

Estes resultados estão de acordo com os encontrados por EDMONDS et al. (1985), que, trabalhando com suínos mestiços desmamados de 28 a 32 dias de idade, demostraram que a adição de 1,5\% de ácido fumárico ou cítrico nas rações, durante a semana pós-desmama, melhorou a conversão alimentar.

FALKOWSKI et al. (1985) concluíram que a adição de 1 ou $2 \%$ de ácido fumárico na dieta de suínos da raça Large White desmamados com 42 dias de idade provocou melhora na conversão alimentar.

$\mathrm{O}$ peso e o rendimento de carcaça de coelhos abatidos aos 80 dias de idade, alimentados com ração contendo níveis de ácido fumárico, encontram-se na Tabela 4.

O teste Dunnett indica que o peso e o rendimento de carcaça de coelhos que receberam rações contendo ácido fumárico foram semelhantes ao 
Rev. bras. zootec.

Tabela 3 - Média de PV aos 80 dias, ganho de peso diário, consumo de ração diário e conversão alimentar de coelhos de 40 a 80 dias de idade, de acordo com diferentes níveis de adição de ácido fumárico nas rações

Table 3 - Mean of LW, daily weigt gain, daily feed intake and feed:gain ratio of rabbits from 40 to 80 days age according to the different levels of fumaric acid addition to the diets

\begin{tabular}{|c|c|c|c|c|c|c|}
\hline \multirow{3}{*}{$\begin{array}{l}\text { Sexo } \\
\text { Sex }\end{array}$} & \multirow{3}{*}{$\begin{array}{c}\text { Test. } \\
\text { Control }\end{array}$} & \multirow{2}{*}{\multicolumn{4}{|c|}{$\begin{array}{c}\text { Nível de ácido fumárico } \\
\text { Level fumaric acid }\end{array}$}} & \multirow{3}{*}{$\begin{array}{c}\text { Média } \\
\text { Mean }\end{array}$} \\
\hline & & & & & & \\
\hline & & 0,5 & 1,0 & 1,5 & 2,0 & \\
\hline \multicolumn{7}{|c|}{$\begin{array}{c}\text { PV aos } 80 \text { dias }(\mathrm{g}) \\
L W \text { at } 80 \text { days }\end{array}$} \\
\hline $\begin{array}{l}\text { Macho } \\
\text { Male }\end{array}$ & 2380 & 2546 & 2525 & 2466 & 2675 & 2518 \\
\hline $\begin{array}{l}\text { Fêmea } \\
\text { Female }\end{array}$ & 2478 & 2478 & 2447 & 2528 & 2683 & 2524 \\
\hline Média & 2429 & 2512 & 2486 & 2497 & 2679 & 2521 \\
\hline
\end{tabular}

Mean

Ganho de peso diário $(\mathrm{g})$

\begin{tabular}{|c|c|c|c|c|c|c|}
\hline \multicolumn{7}{|c|}{ Daily weight gain } \\
\hline Macho & 34 & 38 & 37 & 36 & 41 & 37 \\
\hline Male & & & & & & \\
\hline Fêmea & 37 & 36 & 36 & 38 & 41 & 38 \\
\hline Female & & & & & & \\
\hline Média & 36 & 37 & 37 & 37 & 41 & 37 \\
\hline \multicolumn{7}{|c|}{ Consumo de ração diário(g) } \\
\hline \multicolumn{7}{|c|}{ Daily feed intake } \\
\hline Macho & 131 & 137 & 144 & 139 & 138 & 138 \\
\hline Male & & & & & & \\
\hline Fêmea & 132 & 132 & 133 & 151 & 140 & 138 \\
\hline Female & & & & & & \\
\hline Média & 132 & 135 & 139 & 145 & 139 & 138 \\
\hline \multirow{2}{*}{\multicolumn{7}{|c|}{$\begin{array}{c}\text { Conversão alimentar } \\
\text { Feed:gain ratio }\end{array}$}} \\
\hline & & & & & & \\
\hline Macho & 3,92 & 3,61 & 3,86 & 3,87 & 3,36 & 3,73 \\
\hline Male & & & & & & \\
\hline Fêmea & 3,66 & 3,63 & 3,70 & 4,00 & 3,42 & 3,68 \\
\hline Female & & & & & & \\
\hline Média ${ }^{1}$ & 3,79 & 3,60 & 3,78 & 3,93 & $3,39^{*}$ & 3,70 \\
\hline
\end{tabular}

${ }^{1}$ Efeito quadrático $(P<0,05)$ (Quadratic effect) $\hat{Y}=2,6958+0,0018263 x-0,00000069 X^{2}\left(R^{2}=0,84\right)$.

${ }^{1}$ Quadratic effect $(P<.05) \hat{Y}=2,6958+0,0018263 x-0,00000069 X^{2}\left(R^{2}=0,84\right)$.

${ }^{*}$ Difere da testemunha pelo teste Dunnett $(P<0,05)$.

${ }^{*}$ Differ from control by Dunnett test $(P<.05)$.

peso e ao rendimento de carcaça dos animais que receberam ração testemunha.

A análise de regressão não demonstrou efeito com a adição de ácido fumárico sobre o peso e o rendimento de carcaça de coelhos abatidos aos 80 dias de idade.

Estes resultados são semelhantes aos obtidos por SCAPINELLO et al. (1995), que obtiveram rendimento de carcaça aos 90 dias de idade de $55,56 \%$.

\section{Conclusões}

Considerando o período inicial do experimento, 40 a 70 dias de idade, a adição de ácido fumárico não se mostrou eficiente.

No período total do experimento, a adição de $2 \%$ de ácido fumárico provocou melhora na conversão alimentar, porém mais estudos devem ser realizados no sentido de se verificar a viabilidade de uso em rações para coelhos. 
Tabela 4 - Peso da carcaça e rendimento de carcaça de coelhos abatidos aos 80 dias de idade, de acordo com os diferentes níveis de adição de ácido fumárico às rações

Table 4 - Carcass weight and carcass yield of rabbits slaughtered at 80 days of age according to the different levels of fumaric acid addition to the diets

\begin{tabular}{|c|c|c|c|c|c|c|}
\hline \multirow[t]{2}{*}{$\begin{array}{l}\text { Sexo } \\
\text { Sex }\end{array}$} & \multirow[t]{2}{*}{$\begin{array}{c}\text { Test. } \\
\text { Control }\end{array}$} & \multicolumn{4}{|c|}{$\begin{array}{l}\text { Nível de ácido fumárico } \\
\text { Level fumaric acid }\end{array}$} & \multirow[t]{2}{*}{$\begin{array}{l}\text { Média } \\
\text { Mean }\end{array}$} \\
\hline & & 0,5 & 1,0 & 1,5 & 2,0 & \\
\hline \multicolumn{7}{|c|}{ Peso de carcaça (g) } \\
\hline $\begin{array}{l}\text { Macho } \\
\text { Male }\end{array}$ & 1284 & 1370 & 1352 & 1340 & 1431 & 1355 \\
\hline $\begin{array}{l}\text { Fêmea } \\
\text { Female }\end{array}$ & 1226 & 1338 & 1300 & 1360 & 1434 & 1352 \\
\hline $\begin{array}{l}\text { Média } \\
\text { Mean }\end{array}$ & 1255 & 1354 & 1326 & 1350 & 1433 & 1353 \\
\hline \multicolumn{7}{|c|}{$\begin{array}{c}\text { Rendimento de carcaça (\%) } \\
\text { Carcass vield }\end{array}$} \\
\hline $\begin{array}{l}\text { Macho } \\
\text { Male }\end{array}$ & 54 & 54 & 54 & 54 & 53 & 54 \\
\hline $\begin{array}{l}\text { Fêmea } \\
\text { Female }\end{array}$ & 53 & 54 & 53 & 54 & 53 & 54 \\
\hline $\begin{array}{l}\text { Média } \\
\text { Mean }\end{array}$ & 54 & 54 & 53 & 54 & 53 & 54 \\
\hline
\end{tabular}

\section{Referências Bibliográficas}

AEC. 1987.Recomendações para nutrição animal, 5.ed, RHÔNEPOULENC. $86 \mathrm{p}$.

CASTROVILLI, C. 1991. Acidificazione del mangine per conigli all'engrasso. Rivista di Coniglicoltura, 28(8):31-34.

CROMWELL, G.L. 1989. Nuevos aditivos alimenticios. Industria Porcina, 9(6).

EDMONDS, S.M., IZQUIERDO, A.O., BAKER, H.D. 1985. Feeds additives studies with newly weaned pigs: efficacy of supplemental copper, antibiotics and organic acids. J Anim. Sci., 60(2):462-469.

FALKOWSKI, F.J., AHERNE, X.F. 1984. Fumaric and citric acid as feed additives in starter pig nutrition. J. Anim. Sci., 58(4):935-938.

FALKOWSKI, F.J., MILEWSKA, W., FALKOLWSKA, A. et al. 1985. Results of rearing and some blood indices of piglets fed on feed concetrates containing fumaric acids or probiotic lacto sace. Acta Academical Agriculture ac. Techinical Olstenensis Zootechinica. 20(43):33-41.

GARDNER, R. 1972. Acidulants in food processing. In: CRC Handbook of food additives. Ed Furia TE, Cleveland, OH.

GEDEK, B., ROTH, F.X., KIRCHFESSNER, M. et al. 1992. Influence of fumaric acid, hidrochloric acid, sodium formate, tylosin and toyocerin on the microflora in different segments of gastrointestinal tract. J. Physil. Anim. Nut., 68(4):209-217.
GIESTING, D.W., EASTER, R.A. 1985. Response of starter pigs to supplementation of corn-soybean meal diets with organic acids. J. Anim. Sci., 60(5):1288-1294.

GRAZIOLLI,O., FORNACIARI, S.D., FORNACIARI, I. et al. 1986. L'acidificazione dell'acqua de bevanda nella prevenzeone della patologia enterica del coniglio alle vomento intensivo. Revista di Coniglicoltura, 23(9):65-68.

HOLLISTER, G.A., CHEEK, R.P., ROBINSON, L.K. et al. 1989. Effects of water administred probiotics and acidifers of growth, feed conversion and enterites mortality of wealing rabbits. J. Applied Rabbit Res., 12(4):143-145.

PATTEN, J.D., WALDROUP, P.W. 1988. Use of organic acids in broiler diets. Poult. Sci., 67(6):1178-1182.

SCAPINELLO, C., TAFURI, M.L., ROSTAGNO, H.S. et al. 1995. Níveis de proteína bruta e de energia digestível em dietas para coelhos da raça Nova Zelândia Branco em crescimento. R. Soc. Bras. Zootec., 24(6):981-991.

Recebido em: 12/11/97

Aceito em: 22/01/99 